\title{
A Study on Implementing a Library Process-based Knowledge Management System
}

\author{
Lee, Chi-Lung \\ Director of Library \\ The Affiliated Senior High School of National Taiwan Normal University \\ Taiwan, ROC
}

\begin{abstract}
The importance of knowledge to human development is beyond doubt. Efficient knowledge management can reduce learning time and avoid repeating mistakes. Many enterprises have applied knowledge management in their organizations to increase the knowledge value of their organizations and effectively enhance their competitiveness. This study generalizes a conclusion from the collection of knowledge management process, and proposes the Library Knowledge Management Process (LKMP) of school. According to the LKMP, the study establishes a Library Process-based Knowledge Management System (LPKMS), and designs the questionnaire to collect the opinions of the system users.
\end{abstract}

\section{Introduction}

Knowledge management has been paid great attention in enterprise organizations. However, its applications in secondary schools are rarely studied. Related studies generally show that implementing a knowledge management system positively benefits the performance of school administration.

Considering the fact that integrating knowledge management and information technology into school operation helps to promote the performance of school administration, this study takes the Affiliated Senior High School of National Taiwan Normal University as an example to establish and evaluate a library process-based knowledge management system. This study proposes a knowledge management process that is applicable to secondary school libraries and a knowledge management system that is designed based on this process and incorporates knowledge management into library services, establishes a Library Information Service Knowledge Database with an aim to further develop a digital library and eventually transform into a learning and teaching resource center.

The objectives of this study are as follows:

1. To propose a knowledge management process applicable to libraries based on the literature review of knowledge management processes.

2. Based on the Library Knowledge Management Process (LKMP), to establish a knowledge management system applicable to senior high school libraries named Library Process-based Knowledge Management System (LPKMS). 
3. To use questionnaire surveys and interviews to understand users' feedback on LPKMS.

4. Through the operation of LPKMS, to collect a wide variety of knowledge, establish a Library Information Service Knowledge Database .

\section{Literature Review}

\section{Definition of knowledge}

Knowledge is to the information age as oil was to industrial age (Abar et al., 2004).

Knowledge is defined as a justified belief that increases an entity's capability for effective action (Nonaka and Takeuchi, 1995; Ong and Lai, 2004). Knowledge is a fluid mix of framed experience, values, contextual information, expert insight and grounded intuition that provides an environment and framework for evaluating and incorporating new experiences and information (Tiwana, 2002).

The study is a literary review of academic perspectives on data, information, knowledge, and wisdom. The relationship between the four aspects is illustrated in Figure 1. The descriptions are as follows:

1. Data is the most primitive factual statistic and constitutes the largest quantity. It should be viewed as a primary body.

2. Information is systemized and processed data, serving to convey a designated purpose.

3. Knowledge is the new value that arises from analysis and organized information.

4. Wisdom employs knowledge as its foundation and incorporates other data, information, and individual experiences and skills. It is not a subsidiary of the original data, information, or knowledge, and is a value that arises through transformation. 


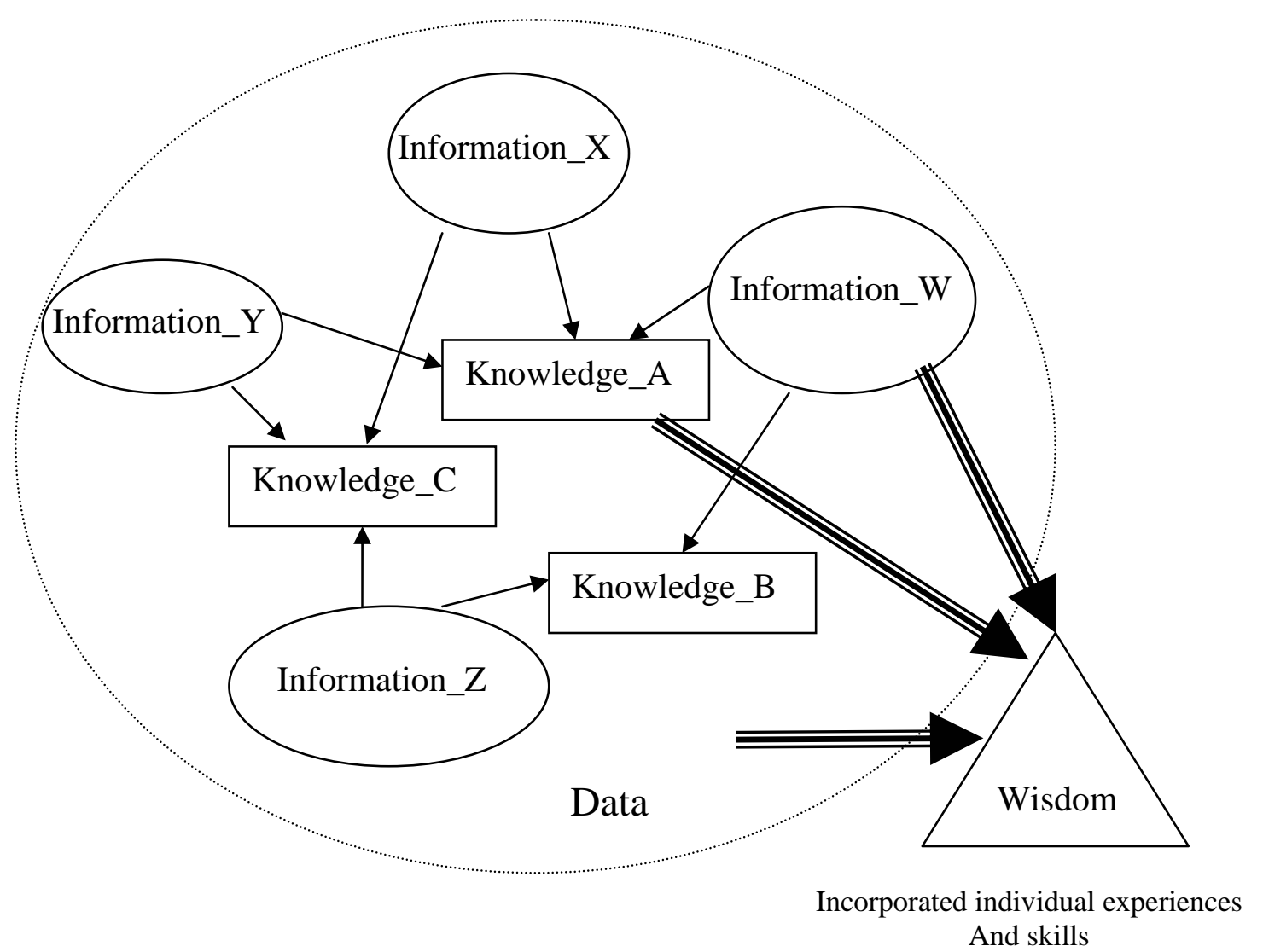

Figure 1 Data, Information, Knowledge and Wisdom

\section{Definition of knowledge management}

The knowledge management is the process of identifying, capturing, and leveraging knowledge to help the company (O’Dell and Grayson, 1998).Knowledge management is the process through which firms create and use their institutional or collective knowledge (Sarvary, 1999). A primary objective of knowledge management research and practice is to facilitate effective and efficient knowledge-sharing among organizational members (Shin, 2004).

Summarizing the above, knowledge management is a procedure in knowledge advancement that utilizes internal knowledge of the organization to improve knowledge and enhance knowledge value of corporations. Knowledge management often requires that people and information technology be brought together. The knowledge manager needs to manage knowledge, and there is no end in knowledge management activities.

\section{Knowledge management process}

The knowledge management includes three sub-processes (Sarvary, 1999).

1. Organizational Learning: The process through which the firm acquires information and knowledge. 
2. Knowledge Production: The process that transforms and integrates raw information into knowledge which in turn is useful to solve business problems.

3. Knowledge Distribution: The process that allows members of the organization to access and use the collective knowledge of the firm.

The knowledge management life cycle is generally described as a sequence of activities. In Table 1, Nissen and Espino (2000) compare the knowledge management life cycles proposed by several researchers, which all share considerable similarities.

Table 1 Knowledge Management Life Cycles

\begin{tabular}{|c|c|c|c|c|c|c|}
\hline Model & Phase1 & Phase2 & Phase3 & Phase4 & Phase5 & Phase6 \\
\hline Nissen & Capture & Organize & & Distribute & Apply & \\
\hline Despres and Chauvel & Create & Map / bundle & Store & Share / transfer & Reuse & Evolve \\
\hline Gartner Group & Create & Organize & Capture & Access & Use & \\
\hline Davenport and Prusak & Generate & & Codify & Transfer & & \\
\hline Amalgamated & Create & Organize & Formalize & Distribute & Apply & Evolve \\
\hline
\end{tabular}

The knowledge management process can divided into four steps, including Knowledge Creation, Knowledge Storage/Retrieval, Knowledge Transfer and Knowledge Application (Alavi and Leidner, 2001).

In Figure 2, the knowledge management value chain can divided four process, including Knowledge Creation, Knowledge Storage, Knowledge Distribution and Knowledge Application (Shin et al, 2001).

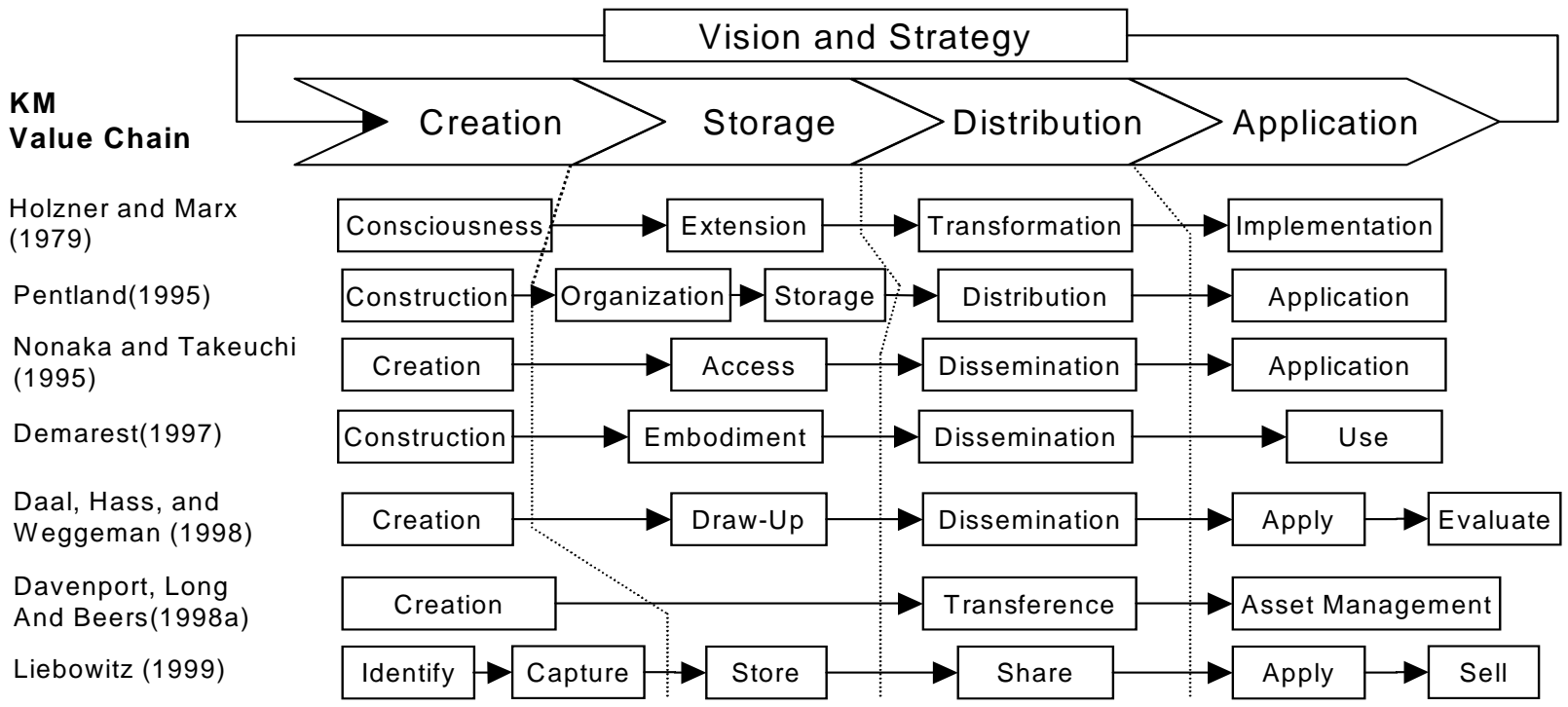

Figure 2 Knowledge Management Value Chain

The three fundamental processes of knowledge management are as follows (Tiwana, 2002): 
1. Knowledge Acquisition: The process of development and creation of insights, skills, and relationships. An experienced stock broker who can see the trend line on a computer monitor and tell which way the market is headed is an example of intuition or acquired knowledge.

2. Knowledge Sharing: Disseminating and making available what is already known. An expert system that helps a novice technical support person answer tech support calls.

3. Knowledge Utilization: Learning is integrated into the organization. Sharing and utilization are taking place simultaneously.

This study generalizes a conclusion from the collection of knowledge management process, and proposes the Library Knowledge Management Process (LKMP) of school. The LKMP was divided into four processes, including knowledge acquisition, knowledge sharing, knowledge application and knowledge feedback.

\section{Knowledge management system architecture}

Technology is able to overcome the barriers of time and space that would otherwise be limiting factors in KM activities. It also serves as a repository in which knowledge can be reliably stored and efficiently retrieved (Chua, 2004). Chua proposes a three-tired knowledge management system architecture. The KMS architecture identifies three distinct services supported by KM technologies. They are infrastructure services, knowledge services and presentation services.

The objective of KMS is to support creation, storage/retrieval, transfer, and application of knowledge in organizations. Knowledge and knowledge management are complex and multifaceted concepts. Table 2 summarizes the four processes and the potential role of IT in facilitating each process (Alavi and Leidner, 2001).

Table 2 Knowledge Management Processes and Potential Role of IT

\begin{tabular}{|c|c|c|c|c|}
\hline $\begin{array}{c}\text { Knowledge } \\
\text { Management } \\
\text { Processes }\end{array}$ & $\begin{array}{c}\text { Knowledge } \\
\text { Creation }\end{array}$ & $\begin{array}{c}\text { Knowledge } \\
\text { Storage/Retrieval }\end{array}$ & $\begin{array}{c}\text { Knowledge } \\
\text { Transfer }\end{array}$ & $\begin{array}{l}\text { Knowledge } \\
\text { Application }\end{array}$ \\
\hline \multirow{3}{*}{$\begin{array}{c}\text { Supporting } \\
\text { Information } \\
\text { Technologies }\end{array}$} & Data Mining & Electronic bulletin boards & Electronic bulletin boards & Expert systems \\
\hline & \multirow{2}{*}{ Learning tools } & \multirow{2}{*}{$\begin{array}{c}\text { Knowledge repositories } \\
\text { Databases }\end{array}$} & Discussion forums & \multirow{2}{*}{$\begin{array}{l}\text { Workflow } \\
\text { systems }\end{array}$} \\
\hline & & & Knowledge directories & \\
\hline \multirow{2}{*}{$\begin{array}{c}\text { Platform } \\
\text { Technologies }\end{array}$} & \multicolumn{4}{|c|}{ Groupware and communication technologies } \\
\hline & \multicolumn{4}{|c|}{ INTRANETS } \\
\hline
\end{tabular}

There are a number of technologies with functionality that is particularly well suited to KMS (Bowman, 2002). The research identifies several technologies that have features useful for KMS, including Intranets, Web authoring tools, Document/content management systems, Search engines, Offices suites, Collaboration software, and Enterprise information portals. 
Based on a literary review of discussions in the construction of knowledge management systems, this research proposed a knowledge management system arising from a process-based perspective. The system features six system modules, including digital work journal module ,

system management module , knowledge bulletin and search module , knowledge discussion and search module , knowledge evaluation module , and e-paper module .

\section{Knowledge management system questionnaire survey design}

A criterion for selection of constructs is that they have been employed frequently in Information System research as a measure of Information System Success. Assessing the validity of Information System success models have five constructs. The Specific constructs included for measurement in the questionnaires are summarized in Table 3 (Rai et al., 2002).

Table 3 Construct Definitions and Measures

\begin{tabular}{|c|c|c|}
\hline Construct & Definition & Measurement Items \\
\hline $\begin{array}{l}\text { Information } \\
\text { Quality }\end{array}$ & $\begin{array}{l}\text { The degree to which } \\
\text { information produced } \\
\text { has the attributes of } \\
\text { content, accuracy, and } \\
\text { format required by the } \\
\text { user. }\end{array}$ & $\begin{array}{l}\text { IQ1. Does SIS provide the precise information you need? } \\
\text { IQ2. Does SIS provide output that is exactly what you need? } \\
\text { IQ3. Does SIS provide sufficient information to enable you to } \\
\text { do your task? } \\
\text { IQ4. Does SIS have errors in the program that you must work } \\
\text { around? } \\
\text { IQ5. Are you satisfied with the accuracy of SIS? } \\
\text { IQ6. Are the output options sufficient for your use? } \\
\text { IQ7. Is the information provided helpful regarding your } \\
\text { questions or problems? }\end{array}$ \\
\hline Ease of Use & $\begin{array}{l}\text { The degree to which the } \\
\text { SIS easy to use. }\end{array}$ & $\begin{array}{l}\text { EOU1. Is SIS user friendly? } \\
\text { EOU2. Is SIS easy to use? }\end{array}$ \\
\hline $\begin{array}{l}\text { Perceived } \\
\text { Usefulness }\end{array}$ & $\begin{array}{l}\text { The degree to which the } \\
\text { user believed that using } \\
\text { a particular system has } \\
\text { enhanced his or her job } \\
\text { performance. }\end{array}$ & $\begin{array}{l}\text { PU1. Using SIS enables me to accomplish student-related tasks } \\
\text { more quickly. } \\
\text { PU2. Using SIS improves my job performance. } \\
\text { PU3. Using SIS in my job increases my productivity. } \\
\text { PU4. Using SIS enhances my effectiveness on the job. } \\
\text { PU5. Using SIS makes it easier to do my job. } \\
\text { PU6. I find SIS useful on my job. }\end{array}$ \\
\hline $\begin{array}{l}\text { User } \\
\text { Satisfaction }\end{array}$ & $\begin{array}{l}\text { The degree of user } \\
\text { satisfaction with the } \\
\text { system. }\end{array}$ & How would you rate your satisfaction with SIS? \\
\hline Utilization & $\begin{array}{l}\text { The degree to which the } \\
\text { user is dependent on the } \\
\text { IS for the execution of } \\
\text { their tasks. }\end{array}$ & I am dependent on SIS. \\
\hline
\end{tabular}

Based on a survey of 120 in Taiwan suggests a 21-item instrument that measures five dimensions of user satisfaction with knowledge management systems is well-validated. The dimensions of user satisfaction with knowledge management systems are including Knowledge Content, Knowledge Map, Knowledge Manipulation, Personalization, and Knowledge Community. (Ong and Lai, 2004)

From a user-oriented perspective, the design of the content, its structure, and presentation of a hypermedia application is likely to affect the user's satisfaction. The web site user 
satisfaction constructs are including Layout, Information, Connection, and Language Customization. (Muylle et al., 2004)

This study summarizes relevant survey questions to organize a library-based questionnaire to understand the usage status by users. The questionnaire is grounded in two points of view. On one hand it serves to understand user receptiveness and sentiment toward knowledge management systems. On the other, the questionnaire explores user receptiveness and sentiment toward information services provided by the library.

\section{Library Knowledge Management Process}

The Library Knowledge Management Process was divided into four processes, including knowledge acquisition, knowledge sharing, knowledge application and knowledge feedback. The four processes of LKMP are as follows:

1. Knowledge Acquisition: Information knowledge is acquired by using information technology to incorporate everyday tasks involving knowledge into system operation. Through the methods in digital work journal composition, relevant information knowledge is acquired. Tacit knowledge is made explicit and archived. The knowledge acquisition procedures are integrated into everyday tasks, avoiding added workload for employees and staff members.

2. Knowledge Sharing: In light of the internet's ease of distribution, the development of associated system modules hopes to achieve the objective of knowledge sharing. The knowledge manger must select the types of knowledge that can be shared, needs to be shared, and is encouraged to be shared. Knowledge sharing is made possible when proper knowledge that suits the needs of the school and is checked by the knowledge manager is made available on the system platform.

3. Knowledge Application: Knowledge application occurs when checked knowledge are accessed or employed in new domains. Through an examination of the selection or response rate of knowledge discussion groups, in addition to the knowledge evaluation results by users, the status of knowledge application are recognized.

4. Knowledge Feedback: After the knowledge management system has operated for a period of time, the knowledge manager will summarize the important knowledge in electronic newsletters and send them to members including knowledge users, constructor, and managers for knowledge feedback purposes. Knowledge feedback can increase the knowledge constructors' enthusiasm in composing digital work journals and increase the participation of knowledge users.

Four knowledge types are constructed based on the categorization of knowledge and the knowledge management processes. They are explained as follows:

1. Tacit Knowledge: Tacit knowledge is knowledge hidden in the minds of knowledge workers and remains to be archived or stored in the knowledge database. 
2. Explicit Knowledge: After tacit knowledge is archived, it transforms into explicit knowledge, which allows for sharing, transfer, or storage.

3. Checked Knowledge: Following the sorting of explicit knowledge by knowledge managers, checked knowledge is selected as contents deserving to be shared with knowledge users.

4. Executive Knowledge: A portion of checked knowledge that is put in use becomes executive knowledge. Executive knowledge is of greater importance and can provide appropriate feedback to knowledge constructors, managers, and users for further interaction and application.

The relationship between the LKMP and Knowledge Types are as Figure 3.

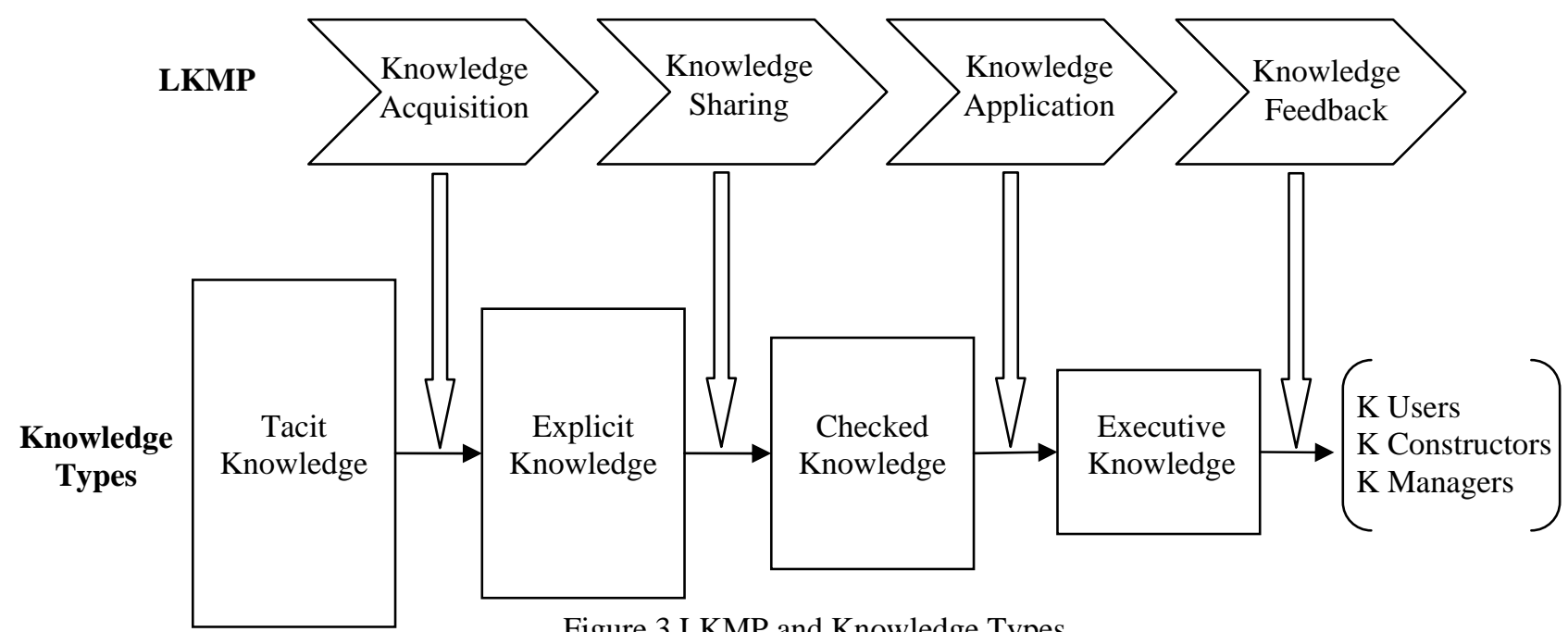

Figure 3 LKMP and Knowledge Types

\section{Library Process-based Knowledge Management System}

\section{Information system development environment}

Due to the lack of school information funding, there is no additional budget for the development or purchase of knowledge management system. Consequently, this study employs free software in the development of the information system. The main programs utilized include: Apache (network server setup software), PHP (server-based programming language), and MySQL (free database software).

Using free software combinations (APM Structure) to develop interactive web database is a trend that is becoming more widespread. Subsequently, if non-profit organizations wish to develop knowledge management system under budgetary constraints, APM Structure can be considered to construct a cheap, manageable, and highly efficient knowledge management system to satisfy the needs in knowledge management. 


\section{LPKMS system modules and operating instructions}

The HSNU LPKMS have six system modules, including digital work journal module , system management module , knowledge bulletin and search module , knowledge discussion and search module , knowledge evaluation module , and e-paper module .

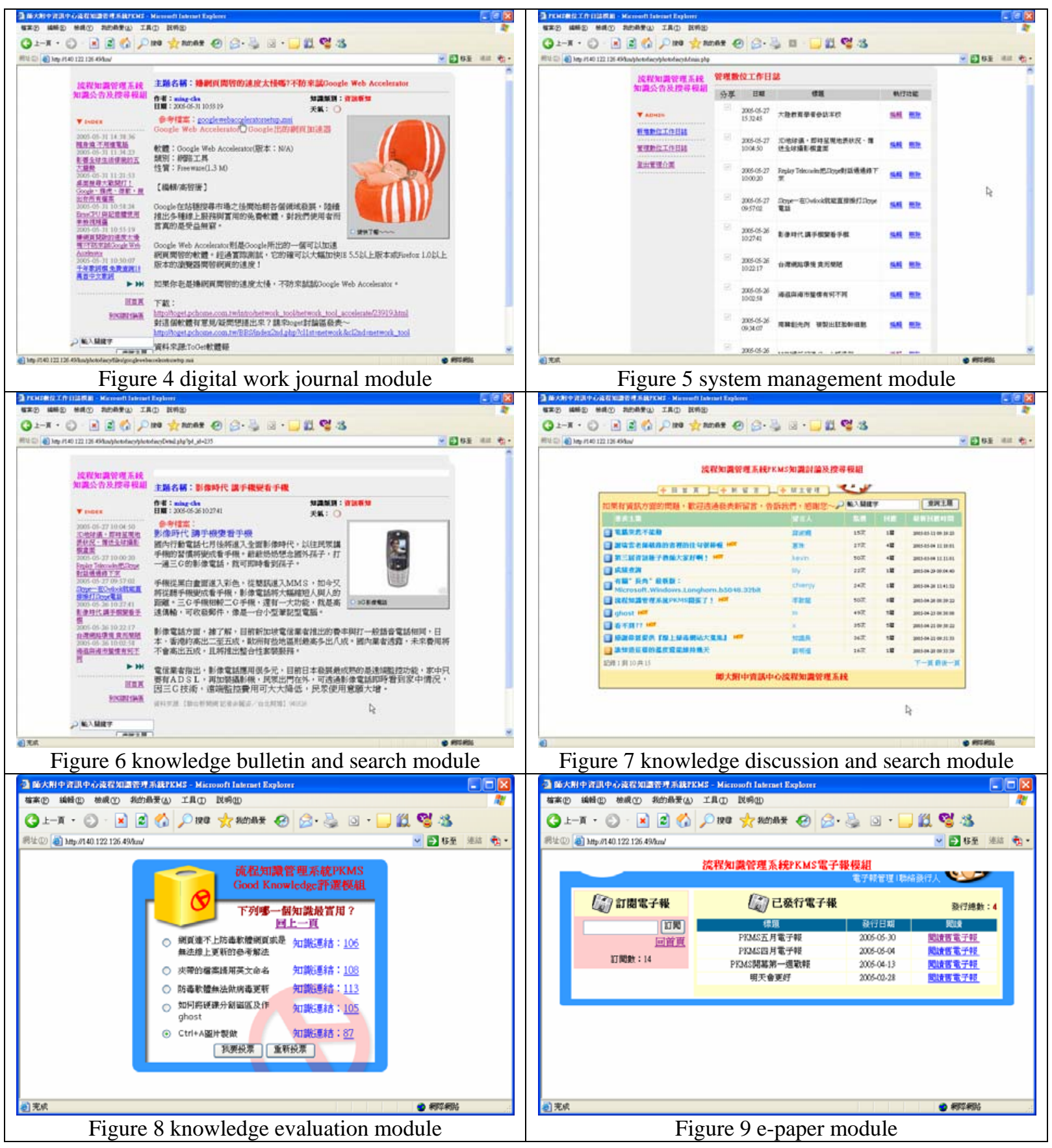




\section{Results and Discussion}

\section{Steps to Promote LPKMS}

The LPKMS system built by this study went online on April 1st of 2005, allowing knowledge constructors to begin digital work journal composition. The LPKMS system was first revealed to the principal and senior administration officers on April 12th during the Eighth Senior Administration Report. The features, operation, and various advantages of the LPKMS system were introduced at the meeting and the system was well-received. The principal pledged to support this research and encourage all senior administrators to join as members and work together in the management of the knowledge management system at the Affiliated Senior High School of National Taiwan Normal University.

Following the meeting, the principal logged on and became a member of the LPKMS system, taking action to show support. On April 13th the system formally connected with the school's official website, allowing the faculty and staff to become members and utilize the LPKMS System. The LPKMS system was introduced during the Third Annual Research Seminar on Information Teachers on April 18th and garnered great support from many participants who immediately became members following the seminar.

\section{User Questionnaires and Results}

This study was adopted Likert Scale method to design user questionnaires. Responses were measured with a five-point scale (1= Strongly Disagree, $2=$ Disagree, $3=$ Undecided, 4= Agree, and $5=$ Strongly Agree). Thus a total numerical value can be calculated from all the responses. Higher item scores indicate greater Agree. 
The user questionnaires and results are as Table 4 .

Table 4 User Questionnaires and Results

\begin{tabular}{|c|c|c|c|}
\hline Construct & Item description & Mean & Std Dev \\
\hline \multirow{6}{*}{$\begin{array}{l}\text { Knowledge } \\
\text { Content } \\
\text { reliability .8593 }\end{array}$} & Q1. LPKMS provides correct content. & 4.30 & .669 \\
\hline & Q2. LPKMS provides integral content. & 3.96 & .649 \\
\hline & Q3. LPKMS provides logical content. & 4.00 & .679 \\
\hline & Q4. The content provided by LPKMS is easy to read. & 4.11 & .641 \\
\hline & Q5. LPKMS provides practicable content. & 4.22 & .577 \\
\hline & \multicolumn{3}{|l|}{ The Average of Means 4.12} \\
\hline \multirow{3}{*}{$\begin{array}{l}\text { Knowledge } \\
\text { Map } \\
\text { reliability .7531 }\end{array}$} & $\begin{array}{l}\text { Q6. The knowledge classification of expertise in the LPKMS } \\
\text { is clear and easy to understand. }\end{array}$ & 4.04 & .854 \\
\hline & $\begin{array}{l}\text { Q7. The knowledge classification of expertise in the LPKMS } \\
\text { is consistent with my cognition. }\end{array}$ & 3.96 & .649 \\
\hline & \multicolumn{3}{|l|}{ The Average of Means 4} \\
\hline \multirow{2}{*}{$\begin{array}{l}\text { Knowledge } \\
\text { Manipulation }\end{array}$} & $\begin{array}{l}\text { Q8. The LPKMS makes it easy for me to search/retrieve } \\
\text { knowledge documents. }\end{array}$ & 4.15 & .718 \\
\hline & \multicolumn{3}{|l|}{ The Average of Mean 4.15} \\
\hline \multirow{5}{*}{$\begin{array}{l}\text { Knowledge } \\
\text { Community } \\
\text { reliability } .8457\end{array}$} & $\begin{array}{l}\text { Q9. The LPKMS makes it convenient for me to discuss with } \\
\text { other people in the knowledge community. }\end{array}$ & 4.26 & .764 \\
\hline & $\begin{array}{l}\text { Q10. The LPKMS makes it convenient for me to input } \\
\text { comments, feedback in the knowledge community. }\end{array}$ & 4.33 & .555 \\
\hline & $\begin{array}{l}\text { Q11. The LPKMS makes it convenient for me to share } \\
\text { knowledge with other people in the knowledge community. }\end{array}$ & 4.41 & .572 \\
\hline & $\begin{array}{l}\text { Q12. The LPKMS makes it convenient for me to access the } \\
\text { shared content from the knowledge community. }\end{array}$ & 4.41 & .501 \\
\hline & \multicolumn{3}{|l|}{ The Average of Means 4.35} \\
\hline \multirow{4}{*}{$\begin{array}{l}\text { Ease of Use } \\
\text { reliability } .8047\end{array}$} & Q13. The LPKMS is easy to use. & 4.37 & .629 \\
\hline & Q14. The LPKMS is user friendly. & 4.26 & .712 \\
\hline & $\begin{array}{l}\text { Q15. The hyperlinks tell me clearly what I can find behind } \\
\text { them. }\end{array}$ & 4.19 & .557 \\
\hline & \multicolumn{3}{|l|}{ The Average of Means 4.27} \\
\hline
\end{tabular}

The average of means of each construct is as Table 5 .

Table 5 the Average of Means of each Construct

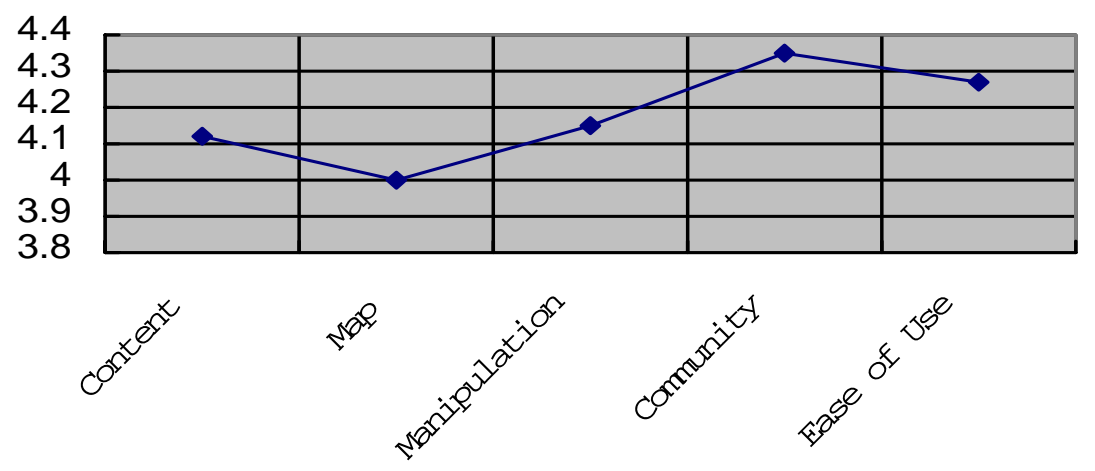


In the questionnaire Part2, we can understand that hundred percent of the colleagues think our school should promote the knowledge management continuously. Nearly have ninety percent of the colleagues think after the library erects the LPKMS, the service quality of the library is promoted. Nearly have ninety six percent of the colleagues think LPKMS is helpful to one's own information knowledge.

\section{Results}

The LPKMS system prototype, built by this study went online after a month. The system received the support and praises of many members at the Affiliated Senior High School of National Taiwan Normal University, including the principal, school evaluation committee members, directors, teachers, and administrative personnel.

Through user questionnaires and interviews, it is found that staff members at the Affiliated Senior High School of National Taiwan Normal University believe that the school should continue its support and advocate the efforts in knowledge management. Many members believe that the LPKMS system provides correct, complete, reasonable, and practical contents that are easy to read, search, and acquire.

The professional knowledge categorization is clear and in touch with users' perception. Knowledge documents are also easy to create, upload, and transfer. In terms of knowledge sharing and discussion groups, the majority of users found the LPKMS system to ease discussions, evaluations, feedbacks, sharing of knowledge, and acquisition of knowledge. In addition, users also thought that the LPKMS system is easily accessible, with a friendly user interface and clear hyperlinks.

\section{Conclusions and Future Development}

\section{Conclusions}

This study generalizes a conclusion from the collection of knowledge management process, and proposes the Library Knowledge Management Process (LKMP) of school. According to the LKMP, the study establishes a Library Process-based Knowledge Management System (LPKMS), and designs the questionnaire to collect the opinions of the system users.

After analyzing the questionnaires of the system users, we have found that they take a positive attitude towards LPKMS, and make some conclusions.

Firstly, the LKMP was divided into four processes, including Knowledge Acquisition , Knowledge Sharing , Knowledge Application and Knowledge Feedback . Secondly, the LKMP is really a practical knowledge management process and LPKMS is actually a useful knowledge management system. Thirdly, all the knowledge documents and conversations will be put into the LPKMS system. With the hard work of LPKMS dedicated users, the Library Information Service Knowledge Database will collect the useful knowledge for school. 
Using LKMP processes as the starting point, apt process modifications are done in hopes of suiting different department needs to establish individual processes. Finally, the knowledge management system is integrated, imparting more effective use to further improve administrative efficiency and teachers' performance of the school and construct a knowledge-based campus that is rooted in information technology.

Aside from establishing the knowledge management platform between the various departments, the system can further expand into individual academic subjects to encourage subject teachers to design lesson plans or teaching materials. Through procedures such as making explicit, archiving, digitizing, and compiling database, teachers' professional knowledge records can be organized to create a knowledge management system for subject teachers. However, such effort requires teachers to be motivated to create subject-based knowledge files. Therefore, an effective reward incentive is perhaps the most important task at hand. At the same time, online learning should be incorporated to allow teachers' knowledge files to be further managed through knowledge management system. Knowledge management and online learning activities must be integrated to further establish a knowledge management system that features online learning mechanisms for students.

Realizing the theories and principles of knowledge management in schools through the assistance of information technology is certainly a viable directive. Integrating knowledge management system and other learning activities to develop a knowledge management platform with online learning functionalities or establish an information campus are possible goals in the future. Given a high degree of agreement between the various levels of school administration to promote the efforts in knowledge management, knowledge management can most certainly be successfully incorporated to improve the organization's efficiency.

The campaign in knowledge management promotion is difficult. When the LPKMS system was put forth at the Affiliated Senior High School of National Taiwan Normal University, the principal's support allowed for little resistance. Nevertheless, increasing the level of participation requires consistent campaigning and clarification. It is hoped that more functions can be added into the knowledge management platform to allow organizational members to voluntarily become system users, sharing the various types of knowledge in the organization to effectively enhance administrative and instructional efficiency.

\section{References}

Abar, S., Abe, T. and Kinoshita, T. (2004), A Next Generation Knowledge Management System Architecture, The 18th International Conference on Advanced Information Networking and Application.

Alavi, M. and Leidner, D. E. (2001), REVIEW: Knowledge Management AND Knowledge Management Systems: Conceptual Foundations AND Research Issues1, 2, MIS Quarterly, Vol. 25 No. 1, pp. 107-136, March.

Bowman, B. J. (2002), Building Knowledge Management Systems, Information Systems Management, pp. 32-40, Summer.

Chua, A. (2004), Knowledge management system architecture: a bridge between KM consultants and technologists, International Journal of Information Management, 24, pp. 87-98. 
Muylle, S., Moenaert, R. and Despontin, M. (2004), The Conceptualization and empirical validation of web site user satisfaction, Information and Management, 41, pp. 543-560.

Nissen, M. E. and Espino, J. (2000), Knowledge Process and System Design for the Coast Guard, Knowledge and Process Management Journal, 7:3, Special Issue, pp. 165-176.

Nissen, M., Kamel, M. and Sengupta, K. (2000), Integrated Analysis and Design of Knowledge Systems and Processes, Information Resources Management Journal, 13, 1, pp. 24-43, Jan-Mar.

Nonaka, I. and Takeuchi, H. (1995), The Knowledge-Creating Company, Oxford University.

O’Dell, C. and Grayson, C. J. (1998), If Only We Knew What We Know: Identification and Transfer of Internal Best Practices, California Management Review, Vol 40, 3, pp. 154-174.

Ong, C. S. and Lai, J. Y. (2004), Developing an instrument for measuring user satisfaction with knowledge management systems, The 37th Hawaii International Conference on System Sciences.

Rai, A., Lang, S. S. and Welker, R. B. (2002), Assessing the Validity of IS Success Models: An Empirical Test and Theoretical Analysis, Information Systems Research, Vol. 13, No. 1, pp. 50-69, March.

Sarvary, M. (1999), Knowledge Management and Competition in the Consulting Industry, California Management Review, Vol 41, 2, pp. 95-107.

Shin, M. (2004), A framework for evaluating economics of knowledge management systems, Information and Management, 42, pp. 179-196.

Shin, M., Holden, T. and Schmidt, R. A. (2001), From Knowledge Theory to Management Practice: Towards and Integrated Approach, Information Processing and Management, 37, pp. 335-355.

Tiwana, A. (2002), The Knowledge Management Toolkit, 2nd ed., Prentice Hall.

\section{Author Note:}

Lee, Chi-Lung, Director of Library at the Affiliated Senior High School of National Taiwan Normal University, has published two SSCl journal papers and presented papers at the international levels. He has two master degrees. One is Information and Computer Education at National Taiwan Normal University and the other is Business and Management at National Chiao Tung University. His major interest lies in developing information systems just like web-based learning system or knowledge management system that contribute to students learning and school administration. 
Reproduced with permission of the copyright owner. Further reproduction prohibited without permission. 